УДК 504.55.054: 622 (470.6)

\title{
ЭФФЕКТИВНОСТЬ КОМБИНИРОВАНИЯ ТЕХНОЛОГИЙ ВЫЕМКИ РУД В ПРЕДЕЛАХ РУДНОГО ПОЛЯ
}

\author{
Голик Владимир Иванович1,2, \\ v.i.golik@mail.ru
}

\author{
Лукьянов Виктор Григорьевич ${ }^{3}$, \\ lukyanov@tpu.ru
}

\author{
Качурин Николай Михайлович4, \\ ecology_tsu_tula@mail.ru
}

\section{Стась Галина Викторовна 4 , galina_stas@mail.ru}

1 Владикавказский научный центр РАН, Россия, 362002, г. Владикавказ, ул. Маркова, 93а

2 Северо-Кавказский государственный технологический университет, Россия, 362021, г. Владикавказ, ул. Космонавта Николаева, 44.

3 Национальный исследовательский Томский политехнический университет, Россия, 634050, г. Томск, пр. Ленина, 30.

4 Тульский государственный университет, Россия, 300012, г. Тула, пр. Ленина, 92.

\begin{abstract}
Актуальность исследования. Статья посвящена актуальной проблеме совершенствования технологии разработки сложно-структурных месторождений скального типа для увеличения производства содержащихся в рудах редких и ценных металлов, дефицитность которых возрастает с развитием научно-технического прогресса.

Цель исследования - определение условий совмещения систем разработки разных классов для увеличения возможностей селективизации добычных работ при использовании различных вариантов извлечения руд в смежных добычных участках.

Методика исследования. Основу исследования составляет экономический расчет возможных вариантов совмещения в пределах рудного поля на основе полученных экспериментально сведений о рудовмещающем массиве.

Результаты. Дана характеристика условий залегания руд на конкретном скальном месторождении сложной структуры. Произведено инженерно-геологическое районирование рудовмещающего массива с диффференцированной оиенкой геологоструктурных нарушений по величине и направленности. Дан прогноз возможного по аналогии с практикой поведения горных выработок под влиянием разломных структур и макротрещин. На уровне экспертной оценки определена целесообразность применения слоевой или камерной систем разработки с закладкой технологических пустот твердеющими смесями.

Выводы. Эфрфективность выемки руд достигается селективизацией выемки запасов в пределах одного рудного поля при комбинировании систем разработки при максимальном учете геолого-структурных фракторов локализации руд и механофризических свойств рудовмещающих пород.
\end{abstract}

\section{Ключевые слова:}

Рудное тело, технология разработки, геологические условия, закладочная смесь, экономический расчет, оптимизация.

\section{Введение}

Состояние горнодобывающей отрасли характеризуется ухудшением технико-экономических показателей освоения недр, в первую очередь, за счет снижения качества добываемых минеральных ресурсов [1-4].

Значительная доля металлических руд добывается из рудных тел, которые отличаются резкими изменениями мощности, угла падения и прочих параметров. Месторождения чаще всего представляют собой изометрическую залежь в породах различного возраста. Участки с повышенным содержанием металла в рудах чередуются с бедными участками. Месторождения рассматриваемого типа чаще всего разрабатываются технологиями с валовой выемкой при геометризации выемочных участков.
Управление горным давлением осуществляется путем оставления целиков, что повышает величину напряжений в массиве, поэтому основным направлением повышения эффективности разработки является применение вариантов сплошной выемки рудного тела.

Сложноструктурные месторождения отличаются системами разломов и трещин, что придает рудовмещающим массивам свойства дискретной среды. Актуальность совершенствования технологии разработки таких месторождений повышается тем, что в них чаще всего локализованы дефицитные редкоземельные, благородные и цветные металлы.

В соответствии с работами М.М. Протодьяконова, В.Д. Слесарева, С.В. Ветрова и др., скальные массивы сохраняют устойчивость при обнажении за счет естественного самозаклинивания структурных блоков. 
Исторически самым ранним способом добычи руд является селективная выемка выработками по руде с открытым выработанным пространством. С появлением средств массового разрушения пород получили развитие технологии с валовой выемкой геометризированных участков. В середине прошлого века появилась технология с закладкой технологических пустот твердеющими смесями [5-8].

Появление высокопроизводительной горной техники и ужесточение требований к полноте выемки руд способствуют селективизации отработки запасов, что породило проблему комбинирования систем разработки в пределах одного рудного поля по экономическому критерию.

Целью работ рассматриваемого направления горного дела является повышение эффективности выемки руд с использованием резервов, одним из которых является оптимизация параметров комбинированной выемки запасов в пределах одного рудного поля [9-11].

\section{Методика исследования}

Инженерно-геологические исследования в стадии детальной разведки месторождения включают:

- выделение типов пород с определением физикомеханических свойств;

- анализ разломной и трещинной структуры массива;

- изучение ослабленности пород в массиве;

- проведение электрометрического каротажа;

- анализ состояния выработок;

- инженерно-геологическое районирование месторождения;

- прогноз устойчивости горно-подготовительных и очистных выработок;

- рекомендации по выбору систем разработки месторождения.

\section{Результаты}

Участок месторождения «Глубинное» (Северный Казахстан) приурочен к зоне регионального субширотного разлома, располагается в южном крыле девонского вулканогенно-терригенного прогиба и вытягивается вдоль разлома на 2 км.

Зона субширотного разлома разделяет массив на геологические блоки.

Южный блок сложен андезитовыми порфиритами и туфами, прорванными интрузиями порфиритов. Породы характеризуются пропилитизацией и хлоритизацией и смяты в складки с углами падения 70-75.

Северный и Центральный блоки сложены осадочно-вулканогенными породами, причем нижнедевонские отложения разделены на верхнюю эффузивную и нижнюю осадочно-туфогенную подсвиты. Породы верхней подсвиты - дацитовые и трахидацитовые порфиры и их кластолавы. Нижняя подсвита представлена туфопесчаниками, алевролитами, туффитами и туфами кислого состава с преобладание мтуфов дацитовых порфиров. Суммарная мощность пород нижней подсвиты 70-400 м. В северном, восточном и западном направлениях мощность подсвиты увеличивается до 500-700 м.
Центральный блок шириной 100-150 м сложен туфами дацитовых порфиров, которые залегают на порфиритах ордовика и прорываются диабазовыми порфиритами. Породы интенсивно подроблены, альбитизированы и падают под углом 30-60.

Зона регионального Широтного разлома представлена серией северо-западных тектонических нарушений, которые вскрыты разведочными выработками в полосе шириной 120-150 м. Наиболее крупными являются крутопадающие Северный и Южный разломы и наклонный Диагональный разлом.

К зоне регионального разлома приурочено развитие карбонатно-натрового метасоматоза (эйситизация). Зона метасоматоза разделяется на внешнюю кальцит-альбитовую с хлоритом и внутреннюю рудную гематит-альбитовую. Внешняя зона захватывает породы Центрального блока, заходя в Южный блок.

Внутренняя зона метасоматитов образует рудные тела. Это оруденелые альбититы по туфам кислого состава, реже по диабазовым порфиритам. Рудные тела располагаются в полосе шириной 50-100 м и вытянутой на 2,0 км. Глубина верхней границы руды 250 м, нижней 730 м. Контакты рудных тел нечеткие. Ширина забалансовых оторочек от 0 до 5 м, чаще 1-2 м. Оруденение прерывистое. В контуры рудных тел включены прослои пород и некондиционных руд мощностью от 1,5 до 5 м. Коэффициент рудоносности для запасов, разведанных по категории $\mathrm{C} 1$, колеблется от 0,51 до 0,83 , составляя в среднем 0,74 .

Рудные тела группируются в рудные зоны. Зоны 1 , 2 и 4 в центральной части месторождения внутри Центрального блока крутопадающие линзо- и штокверкообразные рудные тела мощностью от 3-5 до 30-50 м при средней мощности 5-10 и 10-30 м. Вертикальный размер зоны оруденения в них - от 100 до 250 м.

В зоне 1 сконцентрировано около $70 \%$ запасов, в зоне 2 - $5 \%$, в зоне $4-3 \%$. Рудная зона 3 локализуется в Южном блоке в лежачем крыле Южного разлома. Это жило- и линзообразные крутопадающие тела мощностью от 1 до 45 м, при средней мощности 5-15 м, вмещающие $10 \%$ запасов месторождения.

На восточном фланге месторождения, в зоне регионального широтного разлома, размещены 5-7 рудные зоны, представленные кулисообразными линзами мощностью до 10 м при средней мощности в первые метры. В них сосредоточено примерно 5 \% запасов полезного компонента.

С учетом особенностей геологического строения месторождения произведено инженерно-геологическое районирование массива.

Северный, Центральный и Южный тектонические блоки различаются развитием комплексов пород, напряженностью разломной тектоники, характером и интенсивностью макротрещиноватости пород и ослабленностью пород.

В качестве инженерно-геологических элементов выделяются зоны разломов I и II порядков, разграничивающие районы и участки; зоны влияния разломов I и II порядков в их крыльях; зоны сопряжения разломов I и II порядков; внутренние средне-нарушенные и средне-ослабленные части тектонических блоков; зоны внутриблоковых мелких разломов. 
По инженерно-геологическим условиям месторождение относится к месторождениям средней сложности, приближаясь к простым.

Горные выработки могут разрушаться в неустойчивых породах зон разломов. Их устойчивость ухудшают породы зон влияния разломов, а также сопряжения крупных макротрещин, особенно при расположении выработок вдоль структурных элементов. Возможный устойчивый пролет очистных выработок в малоустойчивых породах не превышает 7-8 м.

Большая часть руд месторождения представляет собой прочные (100-150 МПа), среднеослабленные
$(К о=0,25)$, среднеустойчивые оруденелые альбититы с горизонтальными размерами структурных блоков в 3-4 м. Устойчивый пролет очистных выработок экспертно может быть оценен в 15-20 м.

По этим соображениям часть рудных тел целесообразно отрабатывать слоевой системой разработки, а часть - камерной.

Технико-экономическое обоснование систем разработки проведено для рудных зон Р-1 и Р-2, разведанных по категории $\mathrm{C}_{1}$ и содержащих около половины балансовых запасов месторождения, путем сравнения альтернативных вариантов систем разработки (табл. 1).

Таблица 1. Показатели вариантов систем разработки

Table 1. Indicators of development system options

\begin{tabular}{|c|c|c|c|c|c|}
\hline $\begin{array}{l}\text { Вариант } \\
\text { Option }\end{array}$ & $\begin{array}{c}\text { Горизонтальные слои с закладкой } \\
\text { Bookmark horizontal layers }\end{array}$ & $\begin{array}{c}\text { Подэтажные орты с закладкой } \\
\text { Bookmarked unit vectors }\end{array}$ & $\begin{array}{l}\text { Магазинирование } \\
\text { Shopping }\end{array}$ & $\begin{array}{c}\text { Потери, \% } \\
\text { Loss, \% }\end{array}$ & $\begin{array}{l}\text { Разубоживание, } \% \\
\text { Dilution, } \%\end{array}$ \\
\hline I & 96 & 0 & 4 & 4 & 15 \\
\hline II & 13 & 83 & 4 & 6 & 24 \\
\hline III & 49 & 47 & 4 & 5 & 18 \\
\hline
\end{tabular}

Рудные тела P-1-I и Р-2-(I, 2) из-за низкой устойчивости пород и руд отрабатываются слоевой системой разработки с нисходящей выемкой, а рудное тело Р-I-3 при мощности рудного тела 2-5 м, крутом падении и устойчивых вмещающих породах - с магазинированием руды.

По варианту I рудное тело Р-I-2 (83 \% запасов рудных зон Р-Іи Р-2) отрабатывается слоевой системой разработки, по варианту П - системой подэтажных ортов (штреков), по варианту III - комбинированно системой разработки с магазинированием руды на участках с высоким коэффициентом рудоносности - системой подэтажных ортов (штреков), участки с низким коэффициентом рудоносности - слоевой системой разработки. Удельный вес систем в варианте Ш выбран так, чтобы разубоживаниене превышало $20 \%$.

Проекция рудных зон Р-I и Р-2 на вертикальную плоскость с выделением участков, отрабатываемых системами разработки по варианту Ш дана на рисунке.

Расчетные показатели отработки участков приведены в табл. 2.

Исходные данные для сравнения вариантов систем разработки сведены в табл. 3.

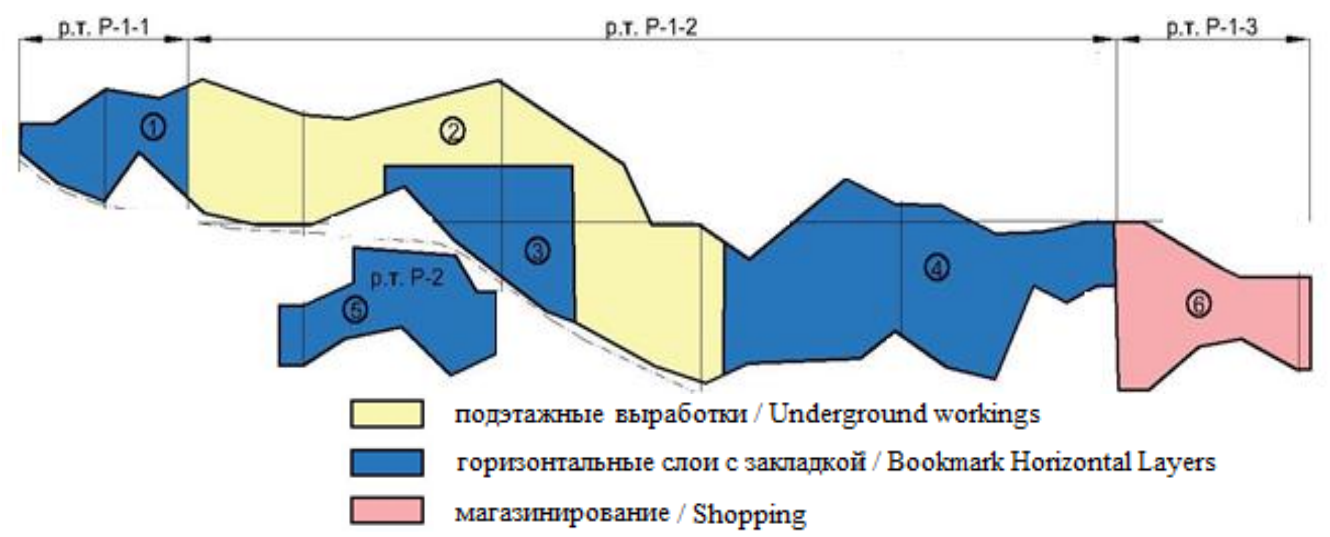

Рисунок. Расположение выемочных участков рудного поля

Figure. Location of excavation sites of the ore field

Таблица 2. Варианты отработки выемочных участков

Table 2. Excavation mining options

\begin{tabular}{|c|c|c|c|c|c|c|c|c|}
\hline \multirow{2}{*}{$\begin{array}{l}\text { № участка } \\
\text { Plot number }\end{array}$} & \multirow{2}{*}{$\begin{array}{l}\text { Доля запасов } \\
\text { Stock share }\end{array}$} & \multirow{2}{*}{$\begin{array}{c}\text { Возможные } \\
\text { Варианты } \\
\text { Possible options }\end{array}$} & \multicolumn{3}{|c|}{ Разубоживание/Dilution, \% } & \multicolumn{3}{|c|}{ Потери/Loss, \% } \\
\hline & & & $\begin{array}{l}\text { слои } \\
\text { layers }\end{array}$ & $\begin{array}{l}\text { камеры } \\
\text { cameras }\end{array}$ & $\begin{array}{l}\text { магазин } \\
\text { score }\end{array}$ & $\begin{array}{l}\text { слои } \\
\text { layers }\end{array}$ & $\begin{array}{c}\text { камеры } \\
\text { layers }\end{array}$ & $\begin{array}{l}\text { магазин } \\
\text { score }\end{array}$ \\
\hline 1 & 4 & слои/layers & 18 & - & - & 4 & - & - \\
\hline 2 & 47 & $\begin{array}{c}\text { слои, камеры } \\
\text { layers, cameras }\end{array}$ & 13 & 19 & - & 4 & 6 & - \\
\hline 3 & 18 & $\begin{array}{c}\text { слои, камеры } \\
\text { layers, cameras }\end{array}$ & 12 & 28 & - & 4 & 6 & - \\
\hline 4 & 18 & $\begin{array}{c}\text { слои, камеры } \\
\text { layers, cameras }\end{array}$ & 19 & 31 & - & 4 & 6 & - \\
\hline 5 & 9 & слои/layers & 21 & - & - & 4 & - & - \\
\hline 6 & 4 & магазин/score & - & - & 23 & - & - & 6 \\
\hline
\end{tabular}


Таблица 3. Показатели вариантов систем разработки

Table 3. Indicators of development system options

\begin{tabular}{|c|c|c|c|c|}
\hline \multirow{2}{*}{ Показатели/Indicators } & \multirow{2}{*}{$\begin{array}{l}\text { Единицы } \\
\text { Units }\end{array}$} & \multicolumn{3}{|c|}{ Варианты/Options } \\
\hline & & I & II & III \\
\hline \multicolumn{5}{|c|}{ Доля в запасах/Share in stocks: } \\
\hline Слои/Layers & $\%$ & 100 & - & 44 \\
\hline Подэтажные выработки/Sub-floor workings & $\%$ & - & 100 & 56 \\
\hline Потери/Losses & $\%$ & 4 & 6 & 5 \\
\hline Разубоживание/Dilution & $\%$ & 14 & 24 & 17 \\
\hline $\begin{array}{l}\text { Доля нарезных и очистных выработок } \\
\text { Share of grooved and stope workings }\end{array}$ & $\begin{array}{l}\mathrm{m}^{3} / \mathrm{T} \\
\mathrm{m}^{3} / \mathrm{t}\end{array}$ & 0,5 & 0,5 & 0,5 \\
\hline $\begin{array}{l}\text { Доля подготовительных выработок } \\
\text { Share of preparatory workings }\end{array}$ & $\begin{array}{l}\mathrm{M}^{3} / \mathrm{M}^{3} \\
\mathrm{~m}^{3} / \mathrm{m}^{3}\end{array}$ & 0,11 & 0,05 & 0,08 \\
\hline $\begin{array}{l}\text { Трудоемкость очистных работ } \\
\text { Complexity of treatment }\end{array}$ & $\begin{array}{c}\text { чел. } \mathrm{cm} / \mathrm{M}^{3} \\
\text { people } \mathrm{cm} / \mathrm{m}^{3}\end{array}$ & 0,13 & 0,07 & 0,09 \\
\hline $\begin{array}{l}\text { Трудоемкость подготовки } \\
\text { Complexity of training }\end{array}$ & $\begin{array}{c}\text { чел. см/ } \mathrm{M}^{3} \\
\text { people } \mathrm{cm} / \mathrm{m}^{3}\end{array}$ & 0,25 & 0,25 & 0,25 \\
\hline $\begin{array}{l}\text { Производительность блока } \\
\text { Block performance }\end{array}$ & $\begin{array}{l}\mathrm{m}^{3} / \mathrm{Mec} . \\
\mathrm{m}^{3} / \text { month }\end{array}$ & 2200 & 5500 & 3700 \\
\hline
\end{tabular}

Для заполнения выработанного пространства могут быть использованы три состава твердеющей закладки, способных обеспечить необходимую проч- ность и транспортабельность, а также позволяющие утилизировать породы от проходки выработок и золу котельной (табл. 4).

Таблица 4. Составы твердеющих смесей

Table 4. Compositions of hardening mixtures

\begin{tabular}{|c|c|c|c|c|}
\hline $\begin{array}{c}\text { Портландцемент } \\
\text { M-400, кг } / \mathrm{M}^{3} \\
\text { Portland cement M- } 400, \mathrm{~kg} / \mathrm{m}^{3}\end{array}$ & 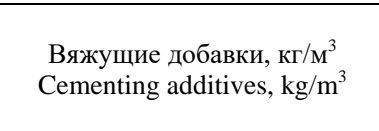 & 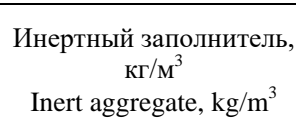 & $\begin{array}{l}\text { Вода, } \\
\text { дм }{ }^{3} / \mathrm{m}^{3} \\
\text { Water, } \\
\mathrm{dm}^{3} / \mathrm{m}^{3}\end{array}$ & $\begin{array}{c}\text { Прочность, } 28 \text { сут., } \\
\text { МПа } \\
\text { Durability, } 28 \text { days, } \\
\text { МПа }\end{array}$ \\
\hline $\begin{array}{c}\text { Состав } 1 \text { расход } 40 \\
\text { Composition } 1 \text {, consumption } 40\end{array}$ & $\begin{array}{c}\text { мокромолотый шлак, } 360 \\
\text { ground slag, } 360\end{array}$ & 1300 & 360 & 4 \\
\hline $\begin{array}{c}\text { Состав } 2 \text { расход } 140 \\
\text { Composition } 2 \text { consumption } 140\end{array}$ & $\begin{array}{l}\text { мокромолотый шлак, } 260 \\
\text { ground slag, 260 }\end{array}$ & 1300 & 360 & 3,9 \\
\hline $\begin{array}{c}\text { Состав } 3 \text { расход } 140 \\
\text { Composition } 3 \text { Consumption } 140\end{array}$ & $\begin{array}{l}\text { измельченные известняки, } 260 \\
\text { ground limestones, } 260\end{array}$ & 1300 & 360 & 2,5 \\
\hline
\end{tabular}

По прочности составы пригодны как для камерной, так и для слоевой систем разработки.

Себестоимость выбранных составов твердеющей закладки оказалась практически одинакова, хотя у варианта с использованием в качестве заполнителя дробленых пород она оказалась несколько больше.

Экономическая оценка возможных вариантов отработки месторождения осуществляется при соблюдении условий:

- при одинаковом годовом погашении балансовых запасов независимо от применяемых вариантов систем разработки;

- при интенсификации погашения балансовых запасов за счет применение в вариантах II и III высокопроизводительной камерной системы разработки (варианты IIa и IIIa с увеличением интенсивности отработки на $15 \%$ и вариант IIб - с увеличением интенсивности отработки на $30 \%$ );

- использование цен по состоянию на 1991 г., поскольку последующие стохастические изменения цен не отражают истинного соотношения стоимостей.

Критерием оценки экономической эффективности сравниваемых вариантов является условная прибыль в расчете на I т балансовых запасов руды (табл. 5).

\section{Обсуждение результатов}

Если интенсивность отработки месторождения определяется не фронтом очистных работ, а технологическими факторами, например, пропускной спо- собностью ствола, производительность рудника может быть обеспечена любым вариантом отработки месторождения (варианты 1, II, III при одинаковом годовом погашении балансовых запасов). Величина условной прибыли на 1 т балансовых запасов по варианту III максимальна и при предельной цене на металл Ц1 составляет 1,43 р. по отношению к варианту 1 и 1,17 р. - по отношению к варианту II. В случае, когда фронт очистных работ ограничен и сдерживает интенсивность отработки месторождения, применение камерной системы разработки с отбойкой руды из подэтажных ортов (штреков) позволяет при тех же площадях повысить концентрацию горных работ и интенсивность отработки месторождения по варианту III на $15 \%$ (вариант IIIa) и по варианту II на $30 \%$ (вариант Пб). Условная прибыль на I т балансовых запасов по вариантам ІІІа и Пб примерно одинакова и при предельной цене на металл, равной Ц ${ }_{1}$, соответственно 2,1 и 2,9 р. Варианты П и II для обеспечения заданной производительности рудника и возможности повышения интенсивности отработки месторождения наиболее надежны.

Результаты исследования подтверждают наличие корреляции между природными и техногенными условиями эксплуатации недр [12-16].

Полученные результаты согласуются с выводами исследователей по обозначенной проблеме горного производства [17-20]. 
Таблица 5. Экономические показатели вариантов разработки

Table 5. Economic performance of development options

\begin{tabular}{|c|c|c|c|c|c|c|}
\hline \multirow{3}{*}{$\begin{array}{l}\text { Ценность добытого из балансовых руд металла, p./т } \\
\text { Value of metal mined from balance ores, rub./t }\end{array}$} & \multicolumn{3}{|c|}{$\begin{array}{l}\text { При стабильном } \\
\text { производстве } \\
\text { With stable produc- } \\
\text { tion }\end{array}$} & \multicolumn{3}{|c|}{$\begin{array}{l}\text { При интенсификации произ- } \\
\text { водства } \\
\text { With the intensification of pro- } \\
\text { duction }\end{array}$} \\
\hline & \multirow[b]{2}{*}{ I } & \multirow{2}{*}{ II } & \multirow{2}{*}{ III } & \multicolumn{2}{|c|}{$15 \%$} & \multirow{2}{*}{$\frac{30 \%}{\text { ІІб }}$} \\
\hline & & & & IIa & IIIa & \\
\hline при Ц ${ }_{1} /$ at $\mathrm{C}_{1}$ & 59,4 & 57,9 & 59,1 & 57,9 & 59,1 & 57,9 \\
\hline при Ц2/at $\mathrm{C}_{2}$ & 82,2 & 80,3 & 81,9 & 80,3 & 81,9 & 80,3 \\
\hline $\begin{array}{l}\text { Условно-переменные затраты на добычу, транспорт и переработку запа- } \\
\text { сов, p./т } \\
\text { Variable costs for production, transportation and processing of reserves, rub./t }\end{array}$ & $\frac{29,2}{28,4}$ & $\frac{27,5}{26,5}$ & $\frac{27,5}{26,8}$ & $\frac{27,2}{25,9}$ & $\frac{27,2}{25,9}$ & $\frac{26,8}{25,5}$ \\
\hline $\begin{array}{l}\text { Дополнительный экономический эффект повышения интенсивности } \\
\text { отработки, p./т } \\
\text { Additional economic effect of increasing the intensity of mining, rub./t }\end{array}$ & - & - & - & $+1,1$ & $+1,1$ & 2,0 \\
\hline Условная прибыль от освоения балансовых запасов, p./т; при Ц 1 & $\underline{30,2}$ & $\underline{30,5}$ & $\underline{31,6}$ & $\underline{31,9}$ & $\underline{33,1}$ & $\underline{33,1}$ \\
\hline Contingent profit from development of balance reserves, rub./t; at $\mathrm{C}_{1}$ & $\overline{31,0}$ & $\overline{31,2}$ & $\overline{32,4}$ & 33,2 & $\overline{34,3}$ & 34,5 \\
\hline при Ц2/at $\mathrm{C}_{2}$ & $\underline{53,1}$ & $\frac{52,8}{53,8}$ & $\underline{54,4}$ & $\frac{54,2}{55,5}$ & $\frac{55,8}{57,1}$ & $\underline{55,4}$ \\
\hline $\begin{array}{l}\text { Экономический эффект, p./т; при Ц } \\
\text { Economic effect, rub./t; at } C_{1}\end{array}$ & 0 & $\frac{+0,3}{+0,3}$ & $\frac{+1,4}{+1,4}$ & $\frac{+1,7}{+2,2}$ & $\frac{+2,9}{+3,3}$ & $\frac{+2,9}{+3,5}$ \\
\hline при Ц2/at $\mathrm{C}_{2}$ & $\frac{-0,2}{-0,1}$ & $\frac{+1,4}{+1,3}$ & $\frac{+1,2}{+1,7}$ & $\frac{+1,2}{+1,8}$ & $\frac{+2,8}{+3,3}$ & $\frac{+2,4}{+3,0}$ \\
\hline
\end{tabular}

Примечание: в числителе - затраты при использовании дробленых пород, в знаменателе - при использовании песка и песчано-гравийной смеси.

Note: the costs when using crushed rocks are in the numerator, the costs when using sand and sand and gravel mix are in the denominator.

\section{Заключение}

При разработке скальных месторождений сложной структуры повышение эффективности выемки руд достигается селективизацией выемки запасов в пределах одного рудного поля за счет комбинирования систем разработки.

\section{СПИСОК ЛИТЕРАТУРЫ}

1. Каплунов Д.Р., Радченко Д.Н. Принципы проектирования и выбор технологий освоения недр, обеспечивающих устойчивое развитие подземных рудников // Горный журнал. - 2017. № 11. - С. 121-125.

2. Тенденции развития минерально-сырьевой базы цветной металлургии России / В.И. Голик, Ю.И. Разоренов, Ю.В. Дмитрак, О.З. Габараев // Известия Тульского государственного университета. Науки о земле. - 2019. - Вып. 2. - С. 117-128.

3. Голик В.И., Захаров Е.И., Абрамкин Н.И. Освоение забалансовых запасов металлических руд // Известия Тульского государственного университета. Науки о земле. - 2018. - Вып. 3. C. $158-170$.

4. Gattinoni P., Pizzarotti E.M., Scesi L. Engineering geology for underground works. -Moscow: Springer, 2014. - 312 p.

5. 3D geological modeling for prediction of subsurface Mo targets in the Luanchuan district, China / G. Wang, R. Li, E.J.M. Carranza, F. Yang // Ore Geology Reviews. - 2015. - V. 71. - P. 592-610.

6. Strategic mining options optimization: Open pit mining, underground mining or both / E. Ben-Awuah, O. Richter, T. Elkington, Y. Pourrahimian // International Journal of Mining Science and Technology. - 2016. - V. 26. - Iss. 6. - P. 1065-1071.

7. Numerical determination of strength and deformability of fractured rock mass by FEM modeling / Y.J. Ping, C.W., Zhong Y.D. Sen, Y.J. Qiang // Computers and Geotechnics. - 2015. V. 64. - P. 20-31.

8. Повышение экономической эффективности горнодобывающих предприятий за счет вовлечения в эксплуатацию техногенных георесурсов / С.Е. Гавришев, С.Н. Корнилов, И.А. Пыталев, И.В. Гапонова // Горный журнал. - 2017. № 12. - C. 46-51.
Оптимизация параметров комбинируемых систем разработки по критерию экономической эффективности возможна при максимальном учете геологоструктурных факторов локализации руд и механофизических свойств рудовмещающих пород, а также утилизации отходов собственного и смежных производств.

9. The provision of development conversion perspectives into undeground one for Russian iron ore deposits development / V.I. Golik, O.Z. Gabaraev, S.A. Maslennikov, Z.M. Khasheva, L.P. Shulgaty // The Social Sciences (Pakistan), - 2016. - V. 11. № 18. - P. 4348-4351

10. Borujeni M.P., Gitinavard H. Evaluating the sustainable mining contractor selection problems: An imprecise last aggregation preference selection index method // Journal of Sustainable Mining. - 2017. - V. 16. - № 4. - P. 207-218.

11. Mineral resources: geological scarcity, market price trends, and future generations / M.L.C.M. Henckens, E.C. van Ierland, P.P.J. Driessen, E. Worrell // Resources Policy. - 2016. - V. 49. P. 102-111.

12. A cost-benefi $t$ analysis of landfill mining and material recycling in China / C. Zhou, Z. Gong, J. Hu, A. Cao, H. Liang // Waste Management. - 2015. - V. 35. - P. 191-198.

13. Минимизация влияния горного производства на окружающую среду / В.И. Голик, Ю.В. Дмитрак, О.З. Габараева, Х.Х. Кожиев // Экология и промышленность России. - 2018. - Т. 22. № 6. - C. 26-29.

14. Adibi N., Ataee-pour M., Rahmanpour M. Integration of sustainable development concepts in open pit mine design // Journal of Cleaner Production. - 2015. - V. 108. - P. 1037-1049.

15. Ensuring safe operation and assessing the condition underground structures by the method of acoustic resonance flaw detection / B. Meskhi, M. Pleshko, Y. Buligin, L. Alexeenko, M. Molev // IOP Conference Series: Earth and Environmental Science. 2017. - P. 212-217.

16. Дмитрак Ю.В., Голик В.И., Вернигор В.В. Геомеханические предпосылки сохранения устойчивости выработок при разработке водообильных месторождений // Известия Тульского 
государственного университета. Науки о Земле. - 2018. № 1. - C. 218-229.

17. Spectral-temporal features of seismic loadings on the basis of strong motion wavelet database / V.B. Zaalishvili, D. Melkov, A.S. Kanukov, B.V. Dzeranov // International Journal of GEOMATE. - 2016. - V. 10. - № 1. - P. 1656-1661.

18. Ляшенко В.И., Дятчин В.З., Лисовой И.А. Повышение экологической безопасности горного производства на основе использования отходов добычи и переработки рудного сырья // Экология и промышленность России. - 2018. - Т. 22. - № 4. C. $4-10$.
19. Волков Е.П., Анушенков А.Н. Разработка технологии закладки горных выработок твердеющими смесями на основе хвостов обогащения // Известия вузов. Горный журнал. - 2019. № 7. - C. 5-13.

20. Мухаметшин В.В., Андреев В.Е. Повышение эффективности оценки результативности технологий, направленных на расширение использования ресурсной базы месторождений с трудноизвлекаемыми запасами // Известия Томского политехнического университета. Инжиниринг георесурсов. - 2018. T. 329. - № 8. - C. 30-26.

Поступила 04.09.2020 г.

\section{Информация об авторах}

Голик В.И., доктор технических наук, профессор, главный научный сотрудник Геофизического института Владикавказского научного центра РАН; профессор кафедры горного дела Северо-Кавказского государственного технологического университета.

Лукьянов В.Г., доктор технических наук, профессор, профессор отделения нефтегазового дела Инженерной школы природных ресурсов Национального исследовательского Томского политехнического университета.

Качурин Н.M., доктор технических наук, профессор, заведующий кафедрой геотехнологии и строительства подземных сооружений, Тульский государственный университет.

Cmacb Г.В., доктор технических наук, доцент кафедры геотехнологии и строительства подземных сооружений, Тульский государственный университет. 
UDC 504.55.054: 622 (470.6)

\title{
EFFICIENCY OF COMBINING ORE MINING TECHNOLOGIES WITHIN AN ORE FIELD
}

\author{
Vladimir I. Golik ${ }^{1,2}$ \\ v.i.golik@mail.ru
}

Victor G. Lukyanov ${ }^{3}$,

lukyanov@tpu.ru

Nikolay M .Kachurin ${ }^{4}$,

ecology_tsu_tula@mail.ru

Galina V. Stas 4 ,

galina_stas@mail.ru

1 Vladikavkaz Scientific Center, Russian Academy of Sciences,

93a, Markov street, Vladikavkaz, 362002, Russia.

2 North Caucasus State Technological University,

44, Cosmonaut Nikolaev street, Vladikavkaz, 362021, Russia.

3 National Research Tomsk Polytechnic University,

30, Lenin avenue, Tomsk, 634050 Russia.

4 Tula State University,

92, Lenin avenue, Tula, 300012, Russia, Russia.

The relevance of the study. The article is devoted to the urgent problem of improving the technology for developing complex structural rocky deposits to increase the production of rare and valuable metals contained in ores, the deficiency of which increases with the development of scientific and technological progress.

The purpose of the study is to determine the conditions for combining development systems of different classes in order to increase the possibilities for selection of mining operations using various options for ore extraction in adjacent mining areas.

The methodology of the study. The basis of the study is the economic calculation of possible combinations within the ore field based on experimentally obtained information about the ore-bearing massif.

Results. The authors have characterized the ore bedding conditions at a specific rock deposit of complex structure, carried out the engineering geological zoning of the rocks of the ore-bearing massif with a differentiated assessment of geological and structural disturbances in magnitude and direction and made the forecast of the possible behavior of mine workings, by analogy with the practice, under the influence of fault structures and macrocracks. At the level of expert evaluation, the appropriateness of using a layered or chamber development system with the laying of technological voids hardening mixtures is determined. For areas containing the main reserves of the ore balance sheet of the deposit, the effectiveness of development systems was assessed by comparing alternative options for layer and chamber excavation, as well as the same shopping.

Conclusions. The efficiency of ore mining is achieved by selection of reserves mining within the same ore field when combining mining systems with the maximum allowance for the geological and structural factors of ore localization and the mechanical and physical properties of ore-bearing rocks.

\section{Key words:}

Ore body, development technology, geological conditions, filling mixture, economic calculation, optimization.

\section{REFERENCES}

1. Kaplunov D.R., Radchenko D.N. Design principles and selection of subsurface development technologies for sustainable development of underground mines. Mining Journal, 2017, no. 11, pp. 121-125. In Rus.

2. Golik V.I., Razorenov Yu.I., Dmitrak Yu.V., Gabaraev O.Z Trends in the development of the mineral resource base of nonferrous metallurgy in Russia. Bulletin of Tula State University. Earth sciences, 2019, Iss. 2, pp. 117-128. In Rus.

3. Golik V.I., Zakharov E.I., Abramkin N.I. Development of offbalance reserves of metal ores. Bulletin of Tula State University. Earth sciences, 2018, Iss. 3, pp. 158-170. In Rus.

4. Gattinoni P., Pizzarotti E. M., Scesi L. Engineering geology for underground works. Moscow, Springer, 2014. $312 \mathrm{p}$.

5. Wang G., Li R., Carranza E.J.M., Yang F. 3D geological modeling for prediction of subsurface Mo targets in the Luanchuan district, China. Ore Geology Reviews, 2015, vol. 71, pp. 592-610.

6. Ben-Awuah E., Richter O., Elkington T., Pourrahimian Y. Strategic mining options optimization: open pit mining, underground mining or both. International Journal of Mining Science and Technology, 2016, vol. 26, Iss. 6, pp. 1065-1071.

7. Ping Y.J., Zhong C.W., Sen Y.D., Qiang Y.J. Numerical determination of strength and deformability of fractured rock mass by FEM modeling. Computers and Geotechnics, 2015, vol. 64, pp. 20-31.

8. Gavrishev S.E., Kornilov S.N., Pytalev I.A., Gaponova I.V. Improving the economic efficiency of mining enterprises by involving technogenic geo-resources in operation. Mining Journal, 2017, no. 12 , pp. 46-51. In Rus.

9. Golik V.I., Gabaraev O.Z., Maslennikov S.A., Khasheva Z.M., Shulgaty L.P. The provision of development conversion perspectives into undeground one for Russian iron ore deposits development. The Social Sciences (Pakistan), 2016, vol. 11, no. 18, pp. $4348-4351$.

10. Borujeni M.P., Gitinavard H. Evaluating the sustainable mining contractor selection problems: An imprecise last aggregation preference selection index method. Journal of Sustainable Mining, 2017, vol. 16, no. 4, pp. 207-218. 
11. Henckens M.L.C.M., Van Ierland E.C., Driessen P.P.J., Worrell E. Mineral resources: Geological scarcity, market price trends, and future generations. Resources Policy, 2016, vol. 49, pp. 102-111.

12. Zhou C., Gong Z., Hu J., Cao A., Liang H. A cost-benefit analysis of landfill mining and material recycling in China. Waste Management, 2015, vol. 35, pp. 191-198.

13. Golik V.I., Dmitrak Yu.V., Gabaraev O.Z., Kozhiev Kh.Kh Minimizing the impact of mining on the environment. Ecology and Industry of Russia, 2018, vol. 22, no. 6, pp. 26-29. In Rus.

14. Adibi N., Ataee-pour M., Rahmanpour M. Integration of sustainable development concepts in open pit mine design. Journal of Cleaner Production, 2015, vol. 108, pp. 1037-1049.

15. Meskhi B., Pleshko M., Buligin Y., Alexeenko L., Molev M. Ensuring safe operation and assessing the condition underground structures by the method of acoustic resonance flaw detection IOP Conference Series: Earth and Environmental Science. 2017. pp. 212-217.

16. Dmitrak Yu.V., Golik V.I., Vernigor V.V. Geomechanical prerequisites for maintaining the stability of workings during the development of water-abundant deposits. Bulletin of the
Tula State University. Earth Sciences, 2018, no. 1, pp. 218-229. In Rus.

17. Zaalishvili V.B., Melkov D., Kanukov A.S., Dzeranov B.V. Spectral-temporal features of seismic loadings on the basis of strong motion wavelet database. International Journal of GEOMATE, 2016, vol. 10, no. 1, pp. 1656-1661.

18. Lyashenko V.I., Dyatchin V.Z., Lisovoy I.A. Improving the environmental safety of mining based on the use of waste from mining and processing of ore raw materials. Ecology and Industry of Russia, 2018, vol. 22, no. 4, pp. 4-10. In Rus.

19. Volkov E.P., Anushenkov A.N. Development of the technology for laying mines with hardening mixtures based on enrichment tailings. Izvestiya Vuzov. Mountain Journal, 2019, no. 7, pp. 5-13. In Rus.

20. Mukhametshin V.V., Andreev V.E. Improving the effectiveness of evaluating the effectiveness of technologies aimed at expanding the use of the resource base of deposits with hard-to-recover reserves. Bulletin of the Tomsk Polytechnic University. Geo Assets Engineering, 2018, vol. 329, no. 8, pp. 26-30. In Rus.

Received: 4 September 2020.

\section{Information about the authors}

Vladimir I. Golik, Dr. Sc., professor, chief researcher, Vladikavkaz Scientific Center, Russian Academy of Sciences; professor, North Caucasus State Technological University.

Victor G. Lukyanov, Dr. Sc., professor, National Research Tomsk Polytechnic University.

Nikolay M.Kachurin, Dr. Sc., professor, Head of the Department of Geotechnology and Construction of Underground Structures, Tula State University.

Galina V. Stas, Dr. Sc., associate professor, Tula State University. 